\title{
The cuttable C-related genotype and allele for the E-cadherin 3'-UTR Pm/ I polymorphism are associated with higher susceptibility to endometriosis
}

\author{
Yao-Yuan Hsieh ${ }^{1,4}$, Chi-Chen Chang ${ }^{1}$, Fuu-Jen Tsai ${ }^{2}$, Chin-Moo Hsu ${ }^{2}$, Cheng-Chieh Lin $^{3}$ \\ and Chang-Hai Tsai ${ }^{2,5}$ \\ ${ }^{1}$ China Medical University Hospital, Department of Obstetrics and Gynecology, Taichung, Taiwan. \\ ${ }^{2}$ China Medical University Hospital, Department of Pediatrics and Medical Genetics, Taichung, Taiwan. \\ ${ }^{3}$ China Medical University Hospital, Department of Family Medicine, Taichung, Taiwan. \\ ${ }^{4}$ National Chiao Tung University, Department of Biological Science and Technology, Hsinchu, Taiwan. \\ ${ }^{5}$ Taichung Health Care and Management University, Taichung, Taiwan.
}

\begin{abstract}
Epithelial cadherin (E-cadherin; CDH1) may influence pericellular proteolysis and intracellular signal transduction, which plays an essential part of tumor invasion. In our study we investigated the correlation between CDH1 gene polymorphism and endometriosis in two groups of pre-menopausal Taiwanese women, group $1(n=150)$ consisting of women with severe stage IV endometriosis and group $2(n=159)$ of women with no endometriosis. The polymerase chain reaction (PCR) was used to identify the cuttable $(C)$ and uncuttable $(T)$ polymorphism of the $\mathrm{CDH} 1-\mathrm{Pm} / \mathrm{I}$ gene (rs1801026) located on the 3'-untranslated region (3'-UTR) of chromosome 16 and compare the genotypes and allelic frequencies of this gene in both groups. We found that the genotype and allele distributions of the $\mathrm{CDH} 1-\mathrm{Pm} / \mathrm{I} \mathrm{C} / \mathrm{T}$ polymorphism were significantly different in both groups. In group 1 the $\mathrm{CDH} 1{ }^{*} \mathrm{C}$ frequency was $47.7 \%$ and the T frequency $52.3 \%$, while the CC homozygote frequency was $6.7 \%$, the TT homozygote $11.3 \%$ and the CT heterozygote $82 \%$. In group 2 the $\mathrm{CDH} 1{ }^{*} \mathrm{C}$ frequency was $17 \%$ and the $\mathrm{T}$ frequency $83 \%$, while the $\mathrm{CC}$ frequency was $0.6 \%$, the TT $66.1 \%$ and the CT $33.3 \%$. These data indicate that the CDH1 gene polymorphism may be associated with the development of severe endometriosis and that the $\mathrm{CDH} 1$ gene $\mathrm{C}$ allele is related to higher susceptibility to endometriosis.
\end{abstract}

Key words: endometriosis, E-cadherin, polymorphism, SNP.

Received: June 25, 2004; Accepted: March 22, 2005.

Endometriosis is one of the most frequent diseases in gynecology. Despite its obscure mechanism, the implantation of endometrial cells from retrograde menstruation into the peritoneum is a widely accepted theory. It is thought that the cell adhesion molecule might play a central role in the development of endometriosis by mediating endometrial-peritoneal cell interactions (Chen et al., 2002). Cadherins are a family of cell adhesion molecules that mediate and regulate homophilic cell-cell adhesion and motility and functions as an invasion suppressor system. Reduced expression of cadherin is observed in numerous cancers (Risinger et al., 1994) and abnormal cadherin molecules may cause dysfunction of the cell-cell adhesion system and trigger cancer invasion and the formation of metastasis (Risinger et al., 1994).

Send correspondence to Fuu-Jen Tsai. China Medical University Hospital, Department of Pediatrics and Medical Genetics, n. 2 Yuh-Der Road, Taichung, Taiwan. E-mail: d0704@www.cmuh. org.tw.
Epithelial E-cadherin 1 (CDH1), a member of the cadherin family of cell surface glycoproteins, is a transmembrane adhesion molecule that plays a key role in intercellular communication and the control of cell growth (Takeichi et al., 1991), loss of which may be associated with the evolution of malignant changes in epithelial tissue (Perl et al., 1998). Kim et al. (2000) pointed out that CDH1 is associated with invasiveness, lymph node metastasis, distant metastasis and other poor prognostic factors, and, therefore, it is logical to suspect that $\mathrm{CDH} 1$ expression might be involved in the development of endometriosis (Poncelet et al., 2002).

In the present paper we describe the results of a study to evaluate whether or not the CDH1-Pml I gene polymorphism is a useful marker for predicting susceptibility to severe endometriosis. The polymerase chain reaction (PCR) was used to identify the cuttable (C) and uncuttable (T) polymorphism of the CDH1-Pml I gene (rs1801026) lo- 
cated on the $3^{\text {' }}$-untranslated region (3'-UTR) of chromosome 16.

Pre-menopausal Taiwanese women patients were divided into two groups, group $1(\mathrm{n}=150)$ consisting of women with surgically diagnosed severe stage IV endometriosis and group $2(\mathrm{n}=159)$ of women with no endometriosis as confirmed during cesarean sections or diagnostic laparoscopy performed by two of the authors (YYH and CCC). There were no significant differences between the members of either of the groups in terms of age, weight or height.

For genotyping, peripheral blood samples were taken from each woman and genomic DNA isolated using the Genomaker DNA extractor kit (Blossom, Taiwan). About $50 \mathrm{ng}$ of genomic DNA was mixed with 20 pmole of each PCR primer in a total volume of 251 containing $10 \mathrm{mM}$ Tris-HCL, $\mathrm{pH} 8.3,50 \mathrm{mM} \mathrm{KCL}, 2 \mathrm{mM} \mathrm{MgCl} 2,0.2 \mathrm{mM}$ of each deoxyribonucleotide triphosphate, and 1 unit of Amplitaq DNA polymerase (Perkin Elmer Applied Biosystems, Foster City, CA, USA). The primer for the CDH1-Pml I C/T gene polymorphism (rs1801026) was designed as follows: forward, 5'-CAGACAAAGAC CAGG ACTAT-3'; reverse, 5'-CACCGACCACCAAAAAGTC GAGGGAA-3'. PCR amplification was performed in a programmable thermal cycler GeneAmp PCR System 2400 (Perkin Elmer Applied Biosystems, Foster City, CA, USA). The cycling condition for the CDH1 gene 3'-untranslated region (UTR) $\mathrm{C} / \mathrm{T}$ polymorphism was set as follows: one cycle at $94{ }^{\circ} \mathrm{C}$ for $5 \mathrm{~min}, 35$ cycles at $94{ }^{\circ} \mathrm{C}$ for $20 \mathrm{~s}, 56^{\circ} \mathrm{C}$ for $20 \mathrm{~s}$, and $72{ }^{\circ} \mathrm{C}$ for $20 \mathrm{~s}$, and one final cycle of extension at $72{ }^{\circ} \mathrm{C}$ for $15 \mathrm{~min}$.

The PCR products were separated by standard methods and the 172-bp product mixed with 2 units of Pml I (New England Biolabs, Beverly, USA) restriction enzyme which (mapping to the 3'-UTR of the CDH1 gene on chromosome 16) and the reaction buffer according to the manufacturer's instructions. The reaction mixture was incubated for $3 \mathrm{~h}$ at $37^{\circ} \mathrm{C}$, after which $10 \mu \mathrm{L}$ of the product mixture was loaded into $3 \%(\mathrm{w} / \mathrm{v})$ agarose gel containing ethidium bromide for electrophoresis. Each allele was recognized according to its fragment size, the cuttable CC homozygote producing $146+26 \mathrm{bp}$ fragments, the uncuttable TT homozygote with a single $172 \mathrm{bp}$ fragment and the CT heterozygote with $172+146+26$ bp fragments. Genotypes and allelic frequencies in both groups were compared using the chi-squared $\left(\chi^{2}\right)$ test (SAS program; Version 8.1, SAS Institute Inc., Cary, North Carolina, USA) with $p<0.05$ being considered statistically significant.

In group 1 the $\mathrm{CDH} 1 * \mathrm{C}$ frequency was $47.7 \%$ and the $\mathrm{T}$ frequency $52.3 \%$, while the CC homozygote frequency was $6.7 \%$, the TT homozygote $11.3 \%$ and the CT heterozygote $82 \%$. In group 2 the $\mathrm{CDH} 1 * \mathrm{C}$ frequency was $17 \%$ and the $\mathrm{T}$ frequency $83 \%$, while the $\mathrm{CC}$ frequency was $0.6 \%$, the TT $66.1 \%$ and the CT $33.3 \%$ (Table 1 ). The $\mathrm{C}$ and $\mathrm{T}$ allele frequencies and genotype proportions of the $\mathrm{CDH} 1-\mathrm{Pml} \mathrm{I} \mathrm{C} / \mathrm{T}$ polymorphisms of the groups were significantly different at $\mathrm{p}=0.0001$. We also observed the cuttable C-related genotype (CC, CT) and C allele are related to higher susceptibility to endometriosis while the uncuttable $\mathrm{T}$ allele is not.

The mechanisms by which cell adhesion molecules mediate the development of endometriosis remain unclear. However, it is known that CDH1 serves as a tumor suppressor and is a calcium-dependent molecule which is found in most epithelial tissue (Chesire et al., 2000) where it is known to play an important role in the development of epithelial structures. Furthermore, CDH1 is a useful tumor marker because altered cadherin expression correlates with increased tumor aggressiveness and un-differentiation in prostate cancer (Chesire et al., 2000) and to uncontrolled proliferation, un-differentiation, invasion and metastasis in gastric and colorectal cancer (Kim et al., 2000). Various authors have also reported that $\mathrm{CDH} 1$ is also associated with embryogenesis, polarization, differentiation and to cell migration in inflamed tissue (Gumbiner 1996; Takeichi et al., 1991).

Table 1 - Genotype and allele frequencies of the CDH1 gene 3'-UTR cuttable (C) and uncuttable (T) polymorphism in women with and without endometriosis. The differences in homozygote genotype and allele frequencies between the two groups were significant at $\mathrm{p}=0.0001$ by the chi-squared test.

\begin{tabular}{|c|c|c|c|c|}
\hline \multirow[t]{2}{*}{ Genotype frequency } & \multicolumn{2}{|c|}{ Group 1 (endometriosis) } & \multicolumn{2}{|c|}{ Group 2 (non-endometriosis) } \\
\hline & Number of women & $\%$ & Number of women & $\%$ \\
\hline CC homozygote & 10 & 6.7 & 1 & 0.6 \\
\hline TT homozygote & 17 & 11.3 & 105 & 66.1 \\
\hline CT heterozygote & 123 & 82 & 53 & 33.3 \\
\hline Total (n) & 150 & & 159 & \\
\hline Allele frequencies & Number of Alleles & $\%$ & Number of Alleles & $\%$ \\
\hline $\mathrm{C}$ & 143 & 47.7 & 54 & 17 \\
\hline $\mathrm{T}$ & 157 & 52.3 & 264 & 83 \\
\hline Total number of alleles (2n) & 300 & - & 318 & - \\
\hline
\end{tabular}


The loss of CDH1 expression is thought to constitute a crucial mechanism in the pathogenesis of endometriosis, endometriotic cells having been found to be nonmalignant epithelial cells lacking CDH1 which acts as an invasion suppressor molecule in carcinomas (Gaetje et al., 1997). Beliard et al. (1997) reported that fibronectin expression persisted around endometriotic glands but not in endometrium despite menstruation in corresponding eutopic endometrium, suggesting that $\mathrm{CDH} 1$ could play a role in the persistence of endometriotic lesions. CDH1 was detected in late luteal phase endometrium by van der Linden et al. (1995) who thought that this cadherin may be involved in the attachment of endometrial fragments to the peritoneal lining during retrograde menstruation and that these cell adhesion molecules could be involved in the shedding of endometrial tissue during menstruation and the attachment of endometrial tissue fragments to the peritoneum (van der Linden et al.,1995). In their study of human endometrium and peritoneal endometriosis, Poncelet et al., (2002) found that ectopic endometriosis (but not eutopic endometrial cells) are invasive in an in vitro collagen assay.

Genetic alterations in any component of the cadherin complex might induce the loss of adhesion function (Oyama et al., 1994) and polymorphisms generated by mutations in the genes might cause decreased, increased or absent gene expression or enzyme activity by multiple molecular mechanisms. Down-regulation of CDH1 protein expression might be correlated with various tumors, including those of the breast (Berx et al., 1996), stomach (Grady et al., 2000), colorectum (Kim et al., 2000), pancreas (Gerdes et al., 1999), lung (Liu et al., 2001) as well as prostate cancer (Li et al., 2001). Kim et al. (2000) have stated that CDH1 mutations are an important step in the carcinogenesis sequence of gastric and colorectal cancer, while Giroldi et al. (2000) found that decreased CDH1 expression was correlated with poor survival of bladder and prostate cancer patients and Perl et al. (1998) reported that CDH1 mediated cell adhesion is one of the rate limiting steps in the progression from adenoma to carcinoma. In contrast, however, Kusano et al. (2001) have suggested that disorders in the CDH1 system may not involved in the carcinogenesis of gastric cancer, while Murant et al. (2000) demonstrated that allele imbalance within the $\mathrm{CDH} 1$ gene is an infrequent event in prostate carcinogenesis. These controversies may be due to the multiple genetic contributions, different disease classification schemes and staging or to variations due to ethnic or environmental factors or in the disease itself. Presumably, the distinct biological condition caused by the CDH1 genotype will be among various genetic, dietary, and environmental factors regulating hormonal and non-hormonal conditions in the development of endometriosis. This polymorphism may also be in linkage disequilibrium with other unidentified functional polymorphisms in cell adhesion molecule genes which also the influence pathogenesis of endometriosis.
In summary, the cuttable C-related genotypes ( $\mathrm{CC}$ homozygote and CT heterozygote) of the CDH1-Pml I gene polymorphism are related to higher risk of endometriosis whereas the uncuttable TT homozygote is related to lower risk. It therefore seems likely that the CDH1 gene polymorphism contributes to the pathogenesis of endometriosis and, after further clarification of its role in endometriosis, more detailed knowledge of this polymorphism might be useful in understanding related complex pathogenesis. Further surveys also seem to be needed to clarify the role of other cell adhesion molecule genes in the development of endometriosis.

\section{References}

Beliard A, Donnez J, Nisolle M and Foidart JM (1997) Localization of laminin, fibronectin, E-cadherin, and integrins in endometrium and endometriosis. Fertil Steril 67:266-672.

Berx G, Cleton-Jansen AM, Strumane K, de Leeuw WJ, Nollet F, van Roy F and Cornelisse C (1996) E-cadherin is inactivated in a majority of invasive human lobular breast cancers by truncation mutations throughout its extracellular domain Oncogene 13:1919-1925.

Chen GT, Tai CT, Yeh LS, Yang TC and Tsai HD (2002) Identification of the cadherin subtypes present in the human peritoneum and endometriotic lesions: potential role for P-cadherin in the development of endometriosis. Mol Reprod Dev 62:289-294.

Chesire DR, Ewing CM, Sauvageot J, Bova GS and Isaacs WB (2000) Detection and analysis of beta-catenin mutations in prostate cancer Prostate 45:323-334.

Gaetje R, Kotzian S, Herrmann G, Baumann R and StarzinskiPowitz A (1997) Nonmalignant epithelial cells, potentially invasive in human endometriosis, lack the tumor suppressor molecule E-cadherin. Am J Pathol 150:461-467.

Gerdes B, Ramaswamy A, Simon B, Pietsch T, Bastian D, Kersting M, Moll R and Bartsch D (1999) Analysis of beta-catenin gene mutations in pancreatic tumors Digestion 60:544-548.

Giroldi LA, Shimazui T, Schalken JA, Yamasaki H and Bringuier PP (2000) Classical cadherins in urological cancers Morphologie 84:31-38.

Grady WM, Willis J, Guilford PJ, Dunbier AK, Toro TT, Lynch H, Wiesner G, Ferguson K, Eng C, Park JG, Kim SJ and Markowitz S (2000) Methylation of the CDH1 promoter as the second genetic hit in hereditary diffuse gastric cancer Nat Genet 26:16-17.

Gumbiner B (1996) Cell adhesion: The molecular basis of tissue architecture and morphogenesis Cell 84:345-357.

Kim HC, Wheeler JM, Kim JC, Ilyas M, Beck NE, Kim BS, Park $\mathrm{KC}$ and Bodmer WF (2000) The E-cadherin gene (CDH1) variants T340A and L599V in gastric and colorectal cancer patients in Korea Gut 47:262-267.

Kusano M, Kakiuchi H, Mihara M, Itoh F, Adachi Y, Ohara M, Hosokawa M and Imai K (2001) Absence of microsatellite instability and germline mutations of E-cadherin, APC and p53 genes in Japanese familial gastric cancer Tumour Biol 22:262-268.

Li LC, Zhao H, Nakajima K, Oh BR, Filho LA, Carroll P and Dahiya R (2001) Methylation of the E-cadherin gene pro- 
moter correlates with progression of prostate cancer J Urol 166:705-709.

Liu D, Huang C, Kameyama K, Hayashi E, Yamauchi A, Kobayashi S and Yokomise H (2001) E-cadherin expression associated with differentiation and prognosis in patients with non-small cell lung cancer Ann Thorac Surg 71:949954.

Murant SJ, Rolley N, Phillips SM, Stower M and Maitland NJ (2000). Allelic imbalance within the E-cadherin gene is an infrequent event in prostate carcinogenesis Genes Chromosomes Cancer 27:104-109.

Oyama T, Kanai Y, Ochiai A, Akimoto S, Oda T, Yanagihara K, Nagafuchi A, Tsukita S, Shibamoto S and Ito F (1994) A truncated beta-catenin disrupts the interaction between Ecadherin and alpha-catenin: A cause of loss of intercellular adhesiveness in human cancer cell lines Cancer Res 54:6282-6287.

Perl AK, Wilgenbus P, Dahl U, Semb H and Christofori G (1998) A causal role for E-cadherin in the transition from adenoma to carcinoma Nature 392:190-193.
Poncelet C, Leblanc M, Walker-Combrouze F, Soriano D, Feldmann G, Madelenat P, Scoazec JY and Darai E (2002) Expression of cadherins and CD44 isoforms in human endometrium and peritoneal endometriosis. Acta Obstet Gynecol Scand 81:195-203.

Risinger JI, Berchuck A, Kohler MF and Boyd J (1994) Mutations of the E-cadherin gene in human gynecologic cancers Nat Genet 7:98-102.

Takeichi M (1991) Cadherine cell adhesion receptor as a morphogenetic regulator Science 251:1451-1455.

van der Linden PJ, de Goeij AF, Dunselman GA, Erkens HW and Evers JL (1995) Expression of cadherins and integrins in human endometrium throughout the menstrual cycle. Fertil Steril 63:1210-1216.

van der Linden PJ, de Goeij AF, Dunselman GA, van der Linden EP, Ramaekers FC and Evers JL (1994) Expression of integrins and E-cadherin in cells from menstrual effluent, endometrium, peritoneal fluid, peritoneum, and endometriosis. Fertil Steril 61:85-90.

Associate Editor: Emmanuel Dias Neto 